\title{
Modelling the Limiting Envelopes of Rocks in the Octahedral Plane
}

\author{
F. Descamps and J.P. Tshibangu \\ Department of Mining Engineering, Faculté Polytechnique de Mons (The Faculty of Engineering, Mons), \\ 53, rue du Joncquois, 7000 Mons - Belgium \\ e-mail: fanny.descamps@fpms.ac.be - jean-pierre.tshibangu@fpms.ac.be
}

Résumé - Modélisation des enveloppes limites des roches dans le plan octaédrique - L'influence de la contrainte principale intermédiaire sur le comportement et les propriétés mécaniques des roches est maintenant largement admise [1-9]. Dans cette étude, nous prenons en compte les trois composantes principales de l'état de contraintes pour construire les enveloppes limites et les modéliser. A cet effet, le recours au plan octaédrique (aussi appelé plan déviatorique ou plan $\pi$ ) convient particulièrement bien pour représenter les résultats. Dans cet article, nous présentons d'abord la méthode automatisée développée pour la construction des enveloppes limites à partir des résultats d'essais polyaxiaux (véritables triaxiaux). Ces développements sont alors appliqués à la construction de l'enveloppe de rupture du Calcaire de Soignies dans différents plans octaédriques. Trois formes d'enveloppes sont mises en évidence : triangulaires, hexagonales et arrondies. La seconde partie de la recherche concerne la modélisation de ces enveloppes de rupture. Depuis le $19^{\text {ème }}$ siècle, beaucoup de critères de résistance ont été développés pour modéliser la réponse de matériaux aux sollicitations et pour identifier le comportement à la rupture sous différents états de contraintes. Parmi ces théories, nous avons retenu les critères de Mohr-Coulomb, Drucker-Prager, Griffith-Murrell et Lade [1, 10-12], dont la représentation octaédrique correspond à la forme des enveloppes limites. Dans des recherches futures, d'autres critères pourraient être envisagés, notamment pour prendre en compte la variabilité des formes octaédriques.

\footnotetext{
Abstract - Modelling the Limiting Envelopes of Rocks in the Octahedral Plane - The influence of the intermediate principal stress on the behaviour and the mechanical properties of rocks is now widely admitted [1-9]. In this study, we take all the three components of the stress state into account for building and modelling limiting envelopes. Therefore, a particularly convenient method for representing the results is the octahedral plane (also called deviatoric plane or $\pi$-plane). In this paper, we first present the automated method we developed for building limiting envelopes from a set of polyaxial (true triaxial) test data. Those developments are then applied for building the failure envelope of the Soignies limestone in various octahedral planes. Three shapes of envelopes are emphasized: triangular, hexagonal and rounded envelopes. The second part of the research deals with the modelling of the failure envelopes. Since the 19th Century, lots of strength criteria have been developed in order to model the materials' intrinsic response to loads and to identify the failure behaviour at different stress states. Among theses theories, we focussed on criteria such as Mohr-Coulomb, Drucker-Prager, Griffith-Murrel and Lade [1, 10-12], for which the octahedral representation looks like our limiting envelopes. In the future, the modelling job could be extended to other criteria, particularly for taking into account the variability of octahedral shapes.
} 


\section{INTRODUCTION}

Representations of load surfaces in the Mohr plane or in the $(P, Q)$ plane (deviatoric stress $Q$ versus mean stress $P$ ) are very widespread. However, researchers [1-9] have emphasized the influence of the intermediate principal stress on the mechanical properties of materials, and particularly of rocks. Some of them developed true triaxial apparatus [1-5]; while others modelled the behaviour either by fitting known criteria to experimental results $[6,7]$ or by developing new criteria $[8,9]$. Our work has been carried out in the framework of Tshibangu's research (1993) who developed a true triaxial device to test small rock samples (30mm-sided cubes). This allowed testing a lot of confining conditions from a homogenous bloc of rock and lead to the complete construction of the failure envelope.

To account for the effect of the intermediate principal stress, it is therefore more appropriate to represent the load surface in the three dimensional principal stress space [13, 14]. However, it is not always easy to visualize clearly a three-dimensional surface from a single view. Therefore, the octahedral representation is more convenient: it "slices" the three dimensional envelope along the hydrostatic axis, like a scanner. It has the advantage of taking into account the influence of the three principal stresses and a plane representation.

In this paper, we first remind how to represent a stress state in the octahedral plane (also called deviatoric plane or $\pi$-plane) and the method we developed for building octahedral limiting envelopes from a set of experimental data expressed in terms of principal stresses. Then, a modelling of the envelopes of some classical failure criteria (MohrCoulomb, Drucker-Prager, Griffith-Murrel, Lade) is proposed and applied to the Soignies limestone.

\section{WORKING IN THE OCTAHEDRAL PLANE}

\subsection{Octahedral Representation of a Stress State}

Load surfaces are often expressed in terms of principal stresses or their invariants. When working in the octahedral plane, it is more convenient to decompose the stress state $\sigma$ $\left(\sigma_{1}, \sigma_{2}, \sigma_{3}\right)$ in a hydrostatic part $\sigma_{o c t}$ and a deviatoric one $\tau_{o c t}$ according to the following relationships [15]:

$$
\begin{gathered}
\sigma_{o c t}=\frac{1}{3}\left(\sigma_{1}+\sigma_{2}+\sigma_{3}\right) \\
\tau_{o c t}=\frac{1}{3} \sqrt{\left(\sigma_{1}-\sigma_{2}\right)^{2}+\left(\sigma_{2}-\sigma_{3}\right)^{2}+\left(\sigma_{3}-\sigma_{1}\right)^{2}}
\end{gathered}
$$

where $\sigma_{1}, \sigma_{2}$ and $\sigma_{3}$ are the major, intermediate and minor principal stresses respectively. The hydrostatic component of stress (or mean stress) defines the position of the octahedral plane along the hydrostatic axis whereas the deviatoric one (or octahedral shear stress) corresponds to the radial coordinate in the octahedral plane.
To completely define the stress state, the Lode angle $\theta$ is to be introduced. It is the angle between the direction of the octahedral shear stress and the projection of the major principal stress axis (Fig. 1). Analytical developments considering the angle between lines of given direction cosines $[1,2]$ lead to:

$$
\cos \theta=\frac{1}{\sqrt{a^{2}+b^{2}+c^{2}}}\left(-\frac{\sqrt{6}}{3} a+\frac{\sqrt{6}}{6} b+\frac{\sqrt{6}}{6} c\right)
$$

where $a, b$ and $c$ are the directions ratios of the octahedral shear stress and are expressed as:

$$
\begin{aligned}
& a=\sigma_{2}+\sigma_{3}-2 \sigma_{1} \\
& b=\sigma_{3}+\sigma_{1}-2 \sigma_{2} \\
& c=\sigma_{1}+\sigma_{2}-2 \sigma_{3}
\end{aligned}
$$

For criteria not depending on the mean stress, the octahedral representation can be normalised with respect to the deviatoric stress corresponding to the triaxial state $\left(\sigma_{2}=\sigma_{3}\right)$. In this case one will be interested mainly in evaluating the shape function of the criterion [10]. As we are dealing with frictional materials it is of high interest not only to focus on the octahedral shape of the criterion but also on its size evolution. The octahedral view as defined here above could also

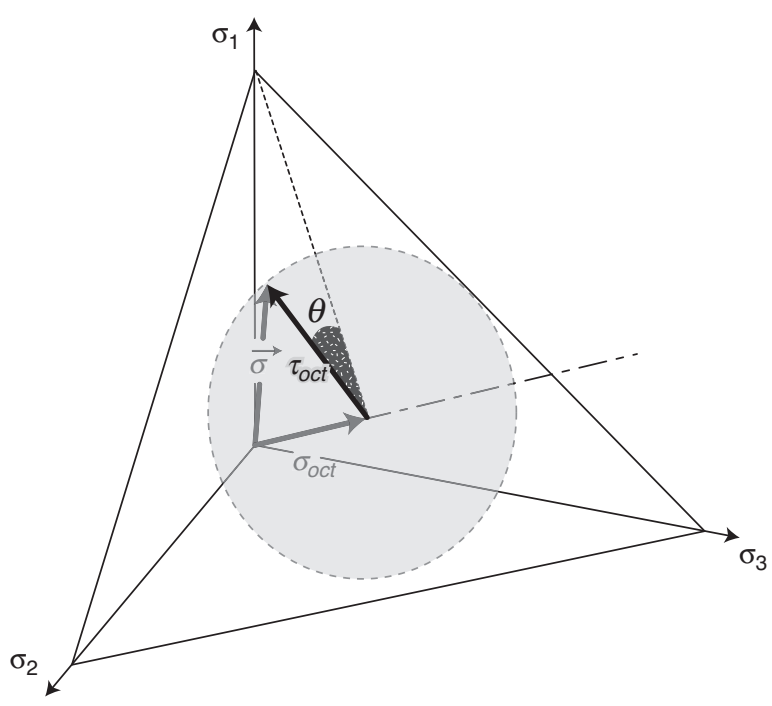

Figure 1

Representation of a stress state $s$ in the principal stresses space and in the octahedral plane. The stress state is decomposed in a hydrostatic part $\sigma_{o c t}$ and a deviatoric one $\tau_{\text {oct }}$. In the octahedral plane, the Lode angle $(\theta)$ gives the direction of $\tau_{o c t}$ with respect to the projection of the major principal stress axis. 
take into account the effect the closure of the load surface for high mean stresses.

\subsection{Experimental System}

In order to emphasize the three-dimensional aspect of the failure envelope, a polyaxial (true triaxial) device was developed a few years ago by Tshibangu (1993). This system has already been described in the literature $[1,2]$ and is illustrated in Figure 2. The cell is composed of three rigid pistons and can develop stresses up to $500 \mathrm{MPa}$ in each direction; this means that minor principal stresses greater than $100 \mathrm{MPa}$ can be set. The overall experimental system comprises the polyaxial cell, a hydraulic bench, a box containing electronic components and a pc equipped with acquisition-command boards to drive the hydraulic bench. A dedicated software has been developed to perform strain or stress controlled compressive tests but also creep, relaxation and biaxial tests.

$30 \mathrm{~mm}$-sided cubes are used to allow a lot of tests from one block of rock. To overcome or limit the side effects the samples are conditioned with Teflon which contributes to reduce the platen/sample friction. Furthermore, Mogi showed that those effects decay when increasing the confining stress to high values [15].

In the general case, the samples are submitted to three different principal stresses $\left(\sigma_{1}>\sigma_{2}>\sigma_{3}>0\right)$. The loading path is such that the three stresses are increased to the desired value of $\sigma_{3}$. Then, $\sigma_{3}$ is kept constant while $\sigma_{1}$ and $\sigma_{2}$ are increased to the desired value of $\sigma_{2}$. Finally, $\sigma_{1}$ is increased until failure occurs. Particular stress paths corresponding to what can be performed on a conventional triaxial system have also been implemented: triaxial compression tests with $\sigma_{2}=\sigma_{3}$ and triaxial extension tests with $\sigma_{2}=\sigma_{1}$. In this paper, those stress paths will be designated as triaxial and biaxial respectively.

\subsection{Octahedral Representation of the Limiting Envelope}

According to our loading path, i.e. setting the intermediate and minor principal stresses before evolving to failure with the major stress, it is not possible to predict in which octahedral plane the failure stress states will be located. In order to get enough information in a particular octahedral plane to represent the limiting envelope, we interpolate curves of the same value of $\sigma_{o c t}$ (iso- $\sigma_{o c t}$ curves) in a $\left(\sigma_{2}, \sigma_{3}\right)$ grid built on experimental data. In this grid (Fig. 3), due to the condition $\sigma_{1} \geq \sigma_{2} \geq \sigma_{3}=0$, the experimental data will be located in an interval limited by two lines: the line of the triaxial states, corresponding to $\sigma_{2}=\sigma_{3}$, and the line of the biaxial states, corresponding to $\sigma_{1}=\sigma_{2}$.

Then, for each interpolation point, the major principal stress can easily be computed using (1):

$$
\sigma_{1}=3 \sigma_{o c t}-\sigma_{2}-\sigma_{3}
$$

So, the principal stresses are known at each interpolation point and the polar coordinates $\left(\tau_{o c t}, \theta\right)$ for the octahedral representation can also be computed using respectively (2) and (3).

In the octahedral plane, the interpolated data correspond to Lode angles ranging from 0 to $60^{\circ}$ because of the $\sigma_{1} \geq \sigma_{2} \geq$ $\sigma_{3}=0$ conditions. Assuming that the material is isotropic, we can close the limiting curve by reproducing 6 times this figure around the hydrostatic axis.

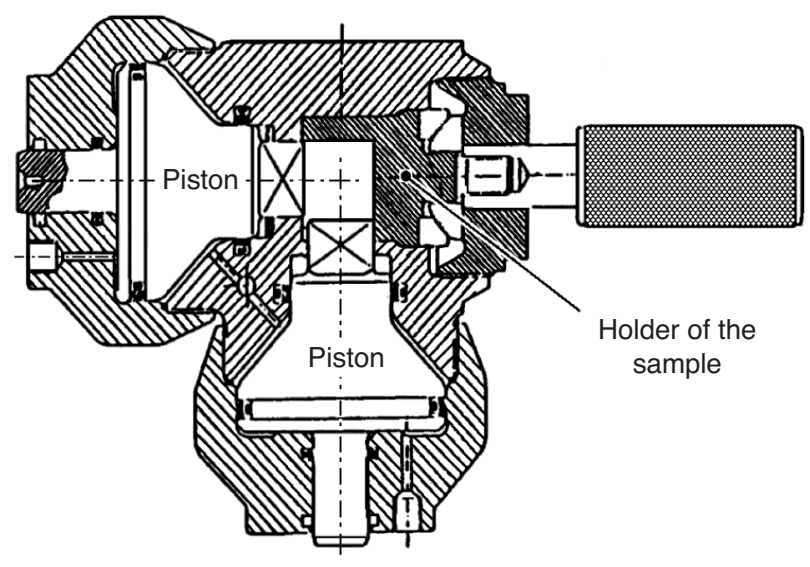

Figure 2

Scheme of the polyaxial cell showing the holder of the sample and two pistons.

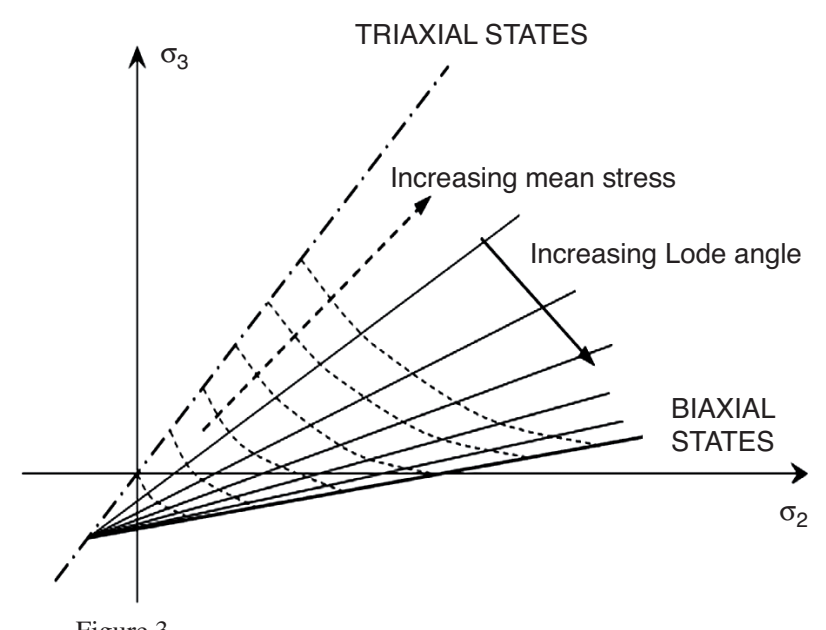

Figure 3

Conceptual view in the $\left(\sigma_{2}, \sigma_{3}\right)$ grid showing the loci of the triaxial compression and triaxial extension (or biaxial) stress states. This graph also shows the iso-curves of the mean stress and of the Lode angle. 


\subsection{Application to the Soignies Limestone}

The Soignies limestone is mined out as ornamental rock in the Mons Region using an open pit method. The behaviour of the material is already well known $[1,2]$ and its main characteristics are reported in Table 1. The rock exhibits brittle failure under atmospheric conditions but undergoes cataclastic flow when subjected to high confining levels. It is also available in sufficient quantity to perform as much tests as needed. These reasons motivated the selection of this rock for the study.

About forty polyaxial tests were carried out, among which triaxial and biaxial stress paths have been implemented. For the triaxial conditions, the confining stresses were set at 0,2 , $10,20,30,40,60,80$ and $90 \mathrm{MPa}$. For the biaxial conditions, the minor principal stress was set to $0,3,5,10,15,20,25,30$ and $35 \mathrm{MPa}$. Table 2 reports the results of the tests, $\sigma_{1 F}$ being the major principal stress at failure.

Using the experimental results, the failure envelope of the rock has been built in the principal stresses space and in octahedral planes for mean stresses ranging from 50 to $210 \mathrm{MPa}$ [13]. The rock is assumed to be isotropic which allows drawing a closed octahedral failure envelope as stated in Section 1.3. Figure 4 illustrates the shape of such a failure envelope in three particular deviatoric planes (90, 130 and $210 \mathrm{MPa}$ ). It shows that this shape varies with the mean stress. For the lowest mean stresses ( $90 \mathrm{MPa}$ ), the failure envelope is almost triangular. This observation suggests that the load surface would probably be better modelled by a Lade-type criterion. But, increasing the mean stress (130 MPa), the failure envelope evolves to a hexagon and the Mohr-Coulomb criterion would be more appropriate. Finally for the highest mean stresses $(210 \mathrm{MPa})$ the envelope seems to become more rounded and a Drucker-Prager or Griffith-Murrel criterion would be adequate.
TABLE 1

Mechanical properties for the Soignies limestone [2]

\begin{tabular}{c|c|c|c|c}
\hline $\begin{array}{c}\rho \\
\left(\mathrm{kg} / \mathrm{m}^{3}\right)\end{array}$ & $\begin{array}{c}T_{0} \\
(\mathrm{MPa})\end{array}$ & $\begin{array}{c}C_{0} \\
(\mathrm{MPa})\end{array}$ & $v$ & $\begin{array}{c}E \\
(\mathrm{MPa})\end{array}$ \\
\hline 2.7 & 8 & 102 & 0.34 & 13200 \\
\hline
\end{tabular}

with $\rho$, the specific gravity; $T_{0}$, the tensile uniaxial strength; $C_{0}$, the compressive uniaxial strength; $v$, the Poisson's ratio; $E$, the Young's modulus.

TABLE 2

Results of the true triaxial compression tests performed on the Soignies limestone

\begin{tabular}{c|c|c|c|c|c}
\hline $\begin{array}{c}\sigma_{1 F}{ }^{\mathrm{a}} \\
(\mathrm{MPa})\end{array}$ & $\begin{array}{c}\sigma_{2} \\
(\mathrm{MPa})\end{array}$ & $\begin{array}{c}\sigma_{3} \\
(\mathrm{MPa})\end{array}$ & $\begin{array}{c}\sigma_{1 F}{ }^{\mathrm{a}} \\
(\mathrm{MPa})\end{array}$ & $\begin{array}{c}\sigma_{2} \\
(\mathrm{MPa})\end{array}$ & $\begin{array}{c}\sigma_{3} \\
(\mathrm{MPa})\end{array}$ \\
\hline 139 & 0 & 0 & 316 & 306 & 20 \\
\hline 171 & 120 & 0 & 348 & 338 & 25 \\
\hline 153 & 146 & 0 & 289 & 30 & 30 \\
\hline 206 & 2 & 2 & 317 & 150 & 30 \\
\hline 227 & 225 & 3 & 360 & 358 & 30 \\
\hline 241 & 237 & 5 & 414 & 413 & 35 \\
\hline 232 & 10 & 10 & 337 & 40 & 40 \\
\hline 186 & 30 & 10 & 355 & 100 & 40 \\
\hline 254 & 50 & 10 & 381 & 120 & 40 \\
\hline 231 & 80 & 10 & 390 & 200 & 40 \\
\hline 242 & 150 & 10 & 420 & 140 & 50 \\
\hline 254 & 250 & 10 & 383 & 60 & 60 \\
\hline 275 & 265 & 15 & 423 & 80 & 60 \\
\hline 280 & 20 & 20 & 473 & 150 & 60 \\
\hline 270 & 40 & 20 & 427 & 170 & 60 \\
\hline 330 & 170 & 20 & 447 & 80 & 80 \\
\hline 309 & 200 & 20 & 471 & 120 & 80 \\
\hline 363 & 230 & 20 & 443 & 90 & 90 \\
\hline$\sigma_{1 F}$ :the major principal stress at failure. & & & \\
\hline
\end{tabular}
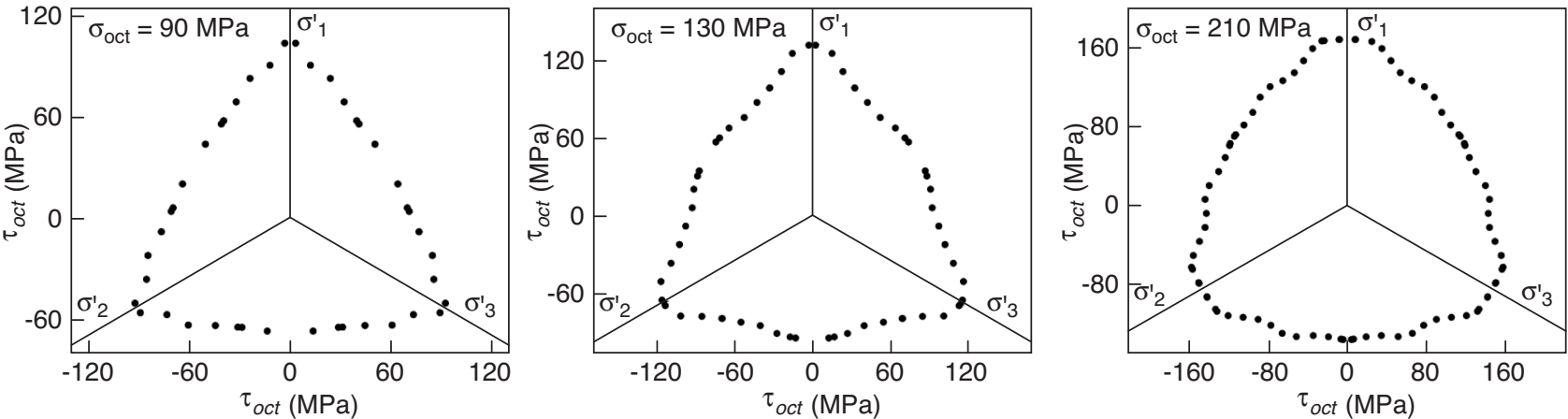

Figure 4

Octahedral failure envelopes of the Soignies limestone for $\sigma_{o c t}=90 \mathrm{MPa}$ (left), $130 \mathrm{MPa}$ (middle) and $210 \mathrm{MPa}$ (right). 


\section{MODELLING THE MOHR-COULOMB CRITERION}

\subsection{The Mohr-Coulomb Criterion}

In three dimensions, the Mohr-Coulomb criterion can be written [1]:

$$
f=\operatorname{Sup}_{i \neq j}\left(\left|\sigma_{i}-q \sigma_{j}\right|\right)-C_{0}=0
$$

with $i, j=1,2$ or 3 . In this expression, $C_{0}$ is the uniaxial compressive strength and $q$ is related to the internal friction angle $\varphi$ by:

$$
q=\tan ^{2}\left(\frac{\pi}{4}+\frac{\varphi}{2}\right)
$$

In the principal stress space, this load surface is a six-sided pyramid inclined along the hydrostatic axis; and in the octahedral plane it is an irregular hexagon as shown in Figure 5 [12].

\subsection{Modelling Methods}

Two methods have been implemented to model the MohrCoulomb criterion. In both cases, the principle is to determine the coordinates of two successive vertices of the irregular hexagon.

The first method [1] is based on modelling the so called intrinsic curve for which the characteristic parameters (friction angle $\varphi$ and cohesion $C$ ) vary with the normal stress. Once the parameters $C$ and $\varphi$ are known the parameters $C_{0}$ and $q$ can also be determined. For a triaxial stress state $\sigma_{\text {oct } T}$, we have:

$$
\sigma_{o c t T}=\frac{1}{3}\left(\sigma_{1}+2 \sigma_{3}\right)
$$

Introducing this relation in (6) leads to the expression of

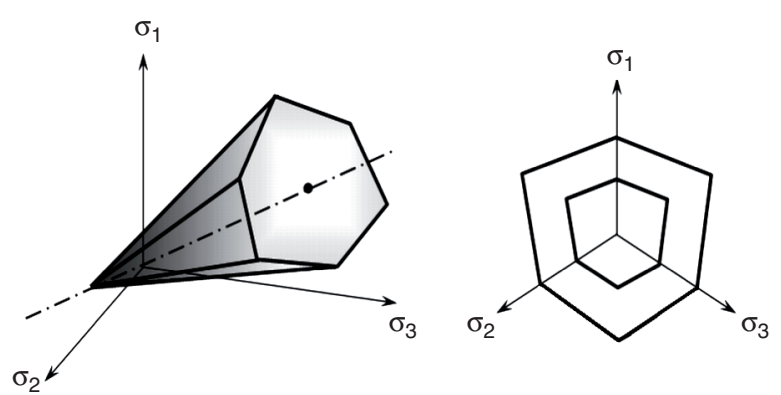

Figure 5

The Mohr-Coulomb criterion in the three-dimensional principal stresses space (left) and in an octahedral view (right). the principal stresses according to the mean stress and the internal friction angle:

$$
\begin{gathered}
\sigma_{1}=\frac{3 q \sigma_{\text {oct } T}+2 C_{0}}{2+q} \\
\sigma_{3}=\frac{3 \sigma_{o c t ~}-C_{0}}{2+q}
\end{gathered}
$$

which in turn allows to compute $\tau_{\text {oct } T}$, the octahedral shear stress for the triaxial state:

$$
\tau_{\text {oct } T}=\sqrt{2} \frac{\sigma_{o c t T}(q-1)+C_{0}}{2+q}
$$

Proceeding the same way for the biaxial state leads to relations (12) to (15) where the subscript $B$ is for "biaxial":

$$
\begin{gathered}
\sigma_{o c t B}=\frac{1}{3}\left(2 \sigma_{1}+\sigma_{3}\right) \\
\sigma_{1}=\frac{3 q \sigma_{o c t B}+C_{0}}{1+2 q} \\
\sigma_{3}=\frac{3 \sigma_{o c t ~}-2 C_{0}}{1+2 q} \\
\tau_{\text {oct } B}=\sqrt{2} \frac{\sigma_{o c t B}(q-1)+C_{0}}{1+2 q}
\end{gathered}
$$

This method is in agreement with Mohr's hypothesis as the intermediate principal stress is not taken into account in the computations.

In the second method, the Mohr-Coulomb criterion is directly modelled in the octahedral plane by performing a linear regression fitting on a set of experimental data for which $0^{\circ} \leq \theta \leq 60^{\circ}$ (least square method). Using the previously mentioned symmetry properties, the irregular MohrCoulomb hexagon can be drawn in each octahedral plane. The values of $\sigma_{\text {oct } T}$ and $\tau_{\text {oct } T}$ give the major and minor principal stresses:

$$
\begin{gathered}
\sigma_{1}=\sigma_{o c t ~}+\sqrt{2} \tau_{\text {oct } T} \\
\sigma_{3}=\sigma_{o c t ~}-\frac{\sqrt{2}}{2} \tau_{\text {oct } T}
\end{gathered}
$$

and allow to compute the parameters of the Mohr-Coulomb criterion for determined confining ranges. In this case, we find the best hexagon fitting the failure envelope in a statistical sense.

\subsection{Fitting the criterion to the Soignies Limestone in the $130 \mathrm{MPa}$ Octahedral Plane}

The failure envelope has been modelled using the two methods described above. 


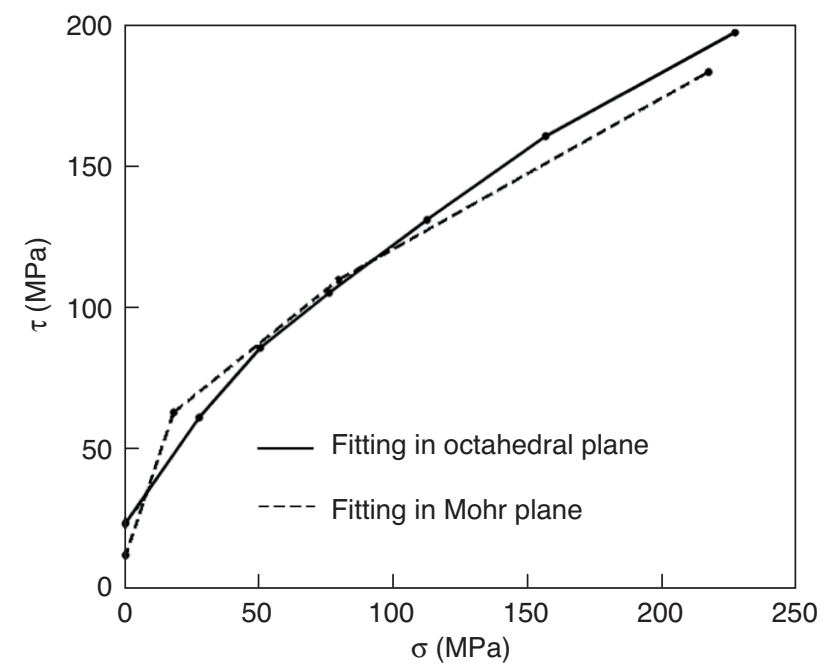

Figure 6

The Mohr-Coulomb criterion in the Mohr plane for the Soignies limestone. The dashed line models the intrinsic curve according to the parameters of Table 3 (first modelling method) whereas the solid line uses the parameters of Table 4 (second modelling method). Both models lead to similar results for this rock.

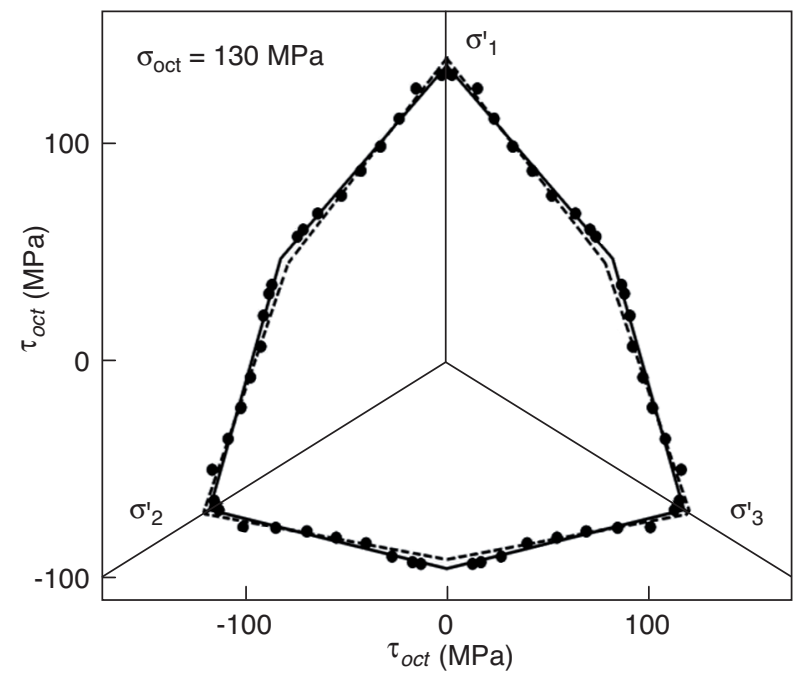

Figure 7

The Mohr-Coulomb failure criterion in the $130 \mathrm{MPa}$ octahedral plane for the Soignies limestone. The dashed line corresponds to the first modelling method and the solid line, to the second method. Both models are very close one to each other and fit well the interpolated data.
In the first case, the parameters of the criterion are determined in the Mohr plane for various normal stress ranges (dashed line in Fig. 6). Table 3 gives the value of the parameters both in the Mohr's and in the principal stress planes. Particularly, for a mean stress of $130 \mathrm{MPa}$, the parameters of the Mohr-Coulomb criterion are: $q=2.78, C_{0}=224 \mathrm{MPa}$, $\varphi=28.1^{\circ}$ and $C=67 \mathrm{MPa}$. Entering the values of $\sigma_{o c t}, q$ and $C_{0}$ in Equation 11 gives an octahedral shear stress of $139 \mathrm{MPa}$ for the triaxial state. The intrinsic curve can also be modelled by considering the biaxial states instead of the triaxial ones, leading to the value of $\tau_{\text {oct } B}(91 \mathrm{MPa})$. So, we have determined the coordinates of two vertices of the irregular hexagon: the first one corresponds to the triaxial state $\left(\tau_{o c t}=139 \mathrm{MPa}, \theta=0^{\circ}\right)$ and the second one, to the biaxial state $\left(\tau_{\text {oct }}=91 \mathrm{MPa}, \theta=60^{\circ}\right)$. The dashed line in Figure 7 shows the resultant criterion in the $130 \mathrm{MPa}$ octahedral plane, together with the interpolated data (dots in this figure, see Sect. 1.2).

The Mohr-Coulomb criterion is also fitted directly in the octahedral planes (second modelling method) by means of linear regression. This gives an octahedral shear stress of $136 \mathrm{MPa}$ for the triaxial state and $95 \mathrm{MPa}$ for the biaxial one. Doing this way, we directly have the criterion in the octahedral plane (solid line in Fig. 7). By performing the regression in all the octahedral planes (50 to $210 \mathrm{MPa}$ ), Equations 16 and 17 enable to compute the corresponding major and minor principal stresses which are given in Table 4, together with the parameters of the criterion in the principal stress plane and in the Mohr plane. For a mean stress of $130 \mathrm{MPa}$, we have $q=3.72, C_{0}=200 \mathrm{MPa}, \varphi=35.5^{\circ}$ and $C=52 \mathrm{MPa}$. Using the values of Table 4 , the results have also been plotted in the Mohr plane (solid line in Fig. 6).

Figures 6 and 7 allow comparing both modelling methods in the Mohr plane and in the octahedral plane. For the Soignies limestone, both methods lead to similar results and are very close to the interpolated data. In other words, we may assume that the Soignies limestone is not very sensitive to the effect of the intermediate principal stress, at least for the considered mean stress.

TABLE 3

Parameters of the Mohr-Coulomb criterion after fitting experimental data in the Mohr plane (first method)

\begin{tabular}{c|c|c|c|c|c|c|c|c}
\hline $\begin{array}{c}\sigma \\
(\mathrm{MPa})\end{array}$ & $\begin{array}{c}\tau \\
(\mathrm{MPa})\end{array}$ & $\begin{array}{c}\varphi \\
\left({ }^{\circ}\right)\end{array}$ & $\begin{array}{c}C \\
(\mathrm{MPa})\end{array}$ & $q$ & $\begin{array}{c}C_{0} \\
(\mathrm{MPa})\end{array}$ & $\begin{array}{c}\sigma_{1} \\
(\mathrm{MPa})\end{array}$ & $\begin{array}{c}\sigma_{3} \\
(\mathrm{MPa})\end{array}$ & $\begin{array}{c}\sigma_{\text {oct }} \\
(\mathrm{MPa})\end{array}$ \\
\hline 0 & 12 & - & - & - & - & 139 & 0 & 46 \\
\hline 18 & 63 & 70.4 & 12 & 33.5 & 139 & 206 & 2 & 70 \\
\hline 79 & 110 & 37.5 & 49 & 4.11 & 198 & 280 & 20 & 107 \\
\hline 218 & 184 & 28.1 & 67 & 2.78 & 224 & 525 & 108 & 247 \\
\hline
\end{tabular}


TABLE 4

Parameters of the Mohr-Coulomb criterion after fitting experimental data in the octahedral planes (second method)

\begin{tabular}{c|c|c|c|c|c|c|c|c}
\hline $\begin{array}{c}\sigma \\
(\mathrm{MPa})\end{array}$ & $\begin{array}{c}\tau \\
(\mathrm{MPa})\end{array}$ & $\begin{array}{c}\varphi \\
\left({ }^{\circ}\right)\end{array}$ & $\begin{array}{c}C \\
(\mathrm{MPa})\end{array}$ & $q$ & $\begin{array}{c}C_{0} \\
(\mathrm{MPa})\end{array}$ & $\begin{array}{c}\sigma_{1} \\
(\mathrm{MPa})\end{array}$ & $\begin{array}{c}\sigma_{3} \\
(\mathrm{MPa})\end{array}$ & $\begin{array}{c}\sigma_{o c t} \\
(\mathrm{MPa})\end{array}$ \\
\hline 0 & 24 & - & - & - & - & 145 & 0 & 48 \\
\hline 28 & 61 & 53.8 & 24 & 9.34 & 145 & 199 & 6 & 70 \\
\hline 50 & 86 & 47.4 & 31 & 6.58 & 161 & 245 & 13 & 90 \\
\hline 76 & 106 & 37.3 & 48 & 4.07 & 193 & 285 & 23 & 110 \\
\hline 112 & 132 & 35.5 & 52 & 3.72 & 200 & 363 & 43 & 150 \\
\hline 157 & 161 & 33.8 & 56 & 3.51 & 211 & 440 & 65 & 190 \\
\hline 227 & 198 & 27.6 & 79 & 2.72 & 262 & 554 & 107 & 256 \\
\hline
\end{tabular}

\section{MODELLING THE DRUCKER-PRAGER CRITERION}

\subsection{The Drucker-Prager Criterion}

The Drucker-Prager criterion is a first generalization of the von Mises'criterion for frictional materials [17, 18]. The yield function is expressed as:

$$
\alpha P+T=k
$$

with

$$
P=\frac{1}{3}\left(\sigma_{1}+\sigma_{2}+\sigma_{3}\right)
$$

$$
T=\sqrt{J_{2}}=\sqrt{\frac{1}{6}\left[\left(\sigma_{1}-\sigma_{2}\right)^{2}+\left(\sigma_{2}-\sigma_{3}\right)^{2}+\left(\sigma_{3}-\sigma_{1}\right)^{2}\right]}
$$

The parameters $\alpha$ and $k$ are material dependent and can be determined from the slope and the intercept of the limiting envelope in the $(P, T)$ plane. $\alpha$ is related to the internal fric-
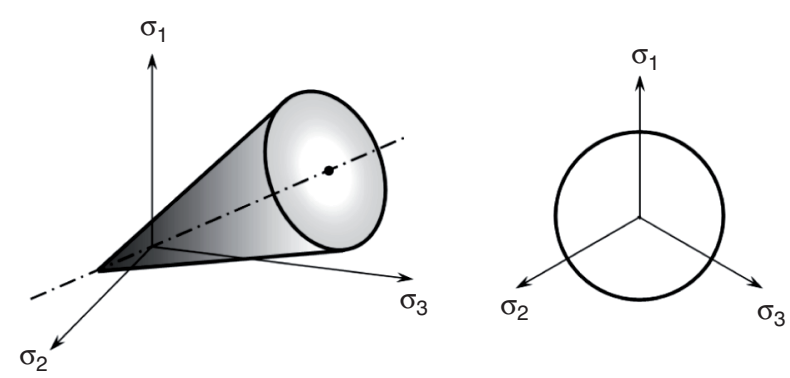

Figure 8

The Drucker-Prager criterion in the three-dimensional principal stresses space (left) and in an octahedral view (right). tion angle of the material; if this parameter is null, the criterion corresponds to Von Mises's criterion. The $k$ coefficient is related to the cohesion of the material $[7,19]$.

In the principal stress space, the criterion is a circular cone inclined along the hydrostatic axis (Fig. 8). The apex of the cone corresponds to $\tau_{\text {oct }}=0 \mathrm{MPa}$, that is:

$$
\sigma_{1}=\sigma_{2}=\sigma_{3}=\frac{-k}{\alpha}
$$

Its intersection with the octahedral plane is a circle, the radius of which equals $\sqrt{6} / 3\left(k-\alpha \sigma_{\text {oct }}\right)$. This criterion is therefore suitable for rounded limiting envelopes.

\subsection{Modelling Method}

To model this criterion in a given octahedral plane, we have to determine the radius of the best circle fitting the data. It is simply given by averaging the octahedral shear stresses in this deviatoric plane:

$$
\tau_{o c t}=\frac{1}{n} \sum_{i=1}^{n} \tau_{o c t i}
$$

where $n$ is the number of interpolated data points verifying the condition $0 \leq \theta \leq 60^{\circ}$.

Proceeding this way, we obtain the radius of the circle in each deviatoric plane, that is, the values of $T$ for various $P$ values. The parameters of the criterion are then computed by fitting a straight line in the $(P, T)$ plane. The parameters will be valid in the interval defined by the $P$ values.

\subsection{Fitting the Criterion to the Soignies Limestone in the $210 \mathrm{MPa}$ Octahedral Plane}

Experimental data on this plane show that the failure envelope is more rounded and suitable for a Drucker-Prager's type criterion. According to Equation 22, the mean value of the octahedral shear stresses in this plane is $150 \mathrm{MPa}$. Figure 9 allows comparing the criterion to the experimental points. Despite the fact that we plotted the mean circle through the data, the discrepancy between this criterion and the experimental envelope can be high (almost $20 \mathrm{MPa}$ for the triaxial state).

Taking all the deviatoric planes into account (from 50 to $210 \mathrm{MPa})$, we fitted the parameters of this criterion in the $(P$, $T)$ plane as stated in Section 3.2. Figure 10 shows that the data are almost linearly distributed in that plane and the parameters $\alpha$ and $k$ are equal to -0.728 and 33.4 respectively. If we compute the radius of the Drucker-Prager's circle from the values of $P, \alpha$ and $k$, we have $152 \mathrm{MPa}$ in the $210 \mathrm{MPa}$ octahedral plane.

The linear distribution of the data in Figure 10 contrasts with the curved shape in the Mohr plane (Fig. 6). It is to notice that Figure 6 only deals with triaxial stress states 


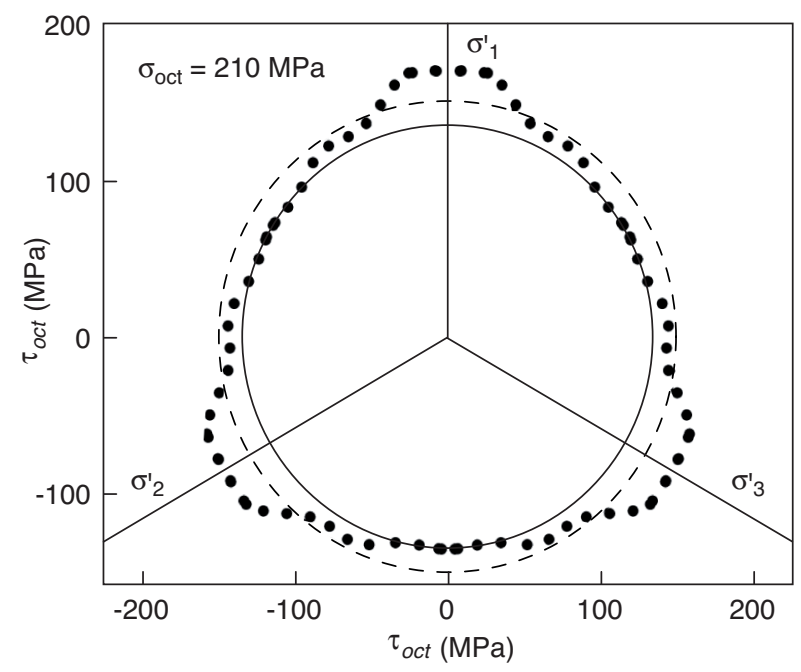

Figure 9

The Drucker-Prager failure criterion in the $210 \mathrm{MPa}$ octahedral plane for the Soignies limestone.

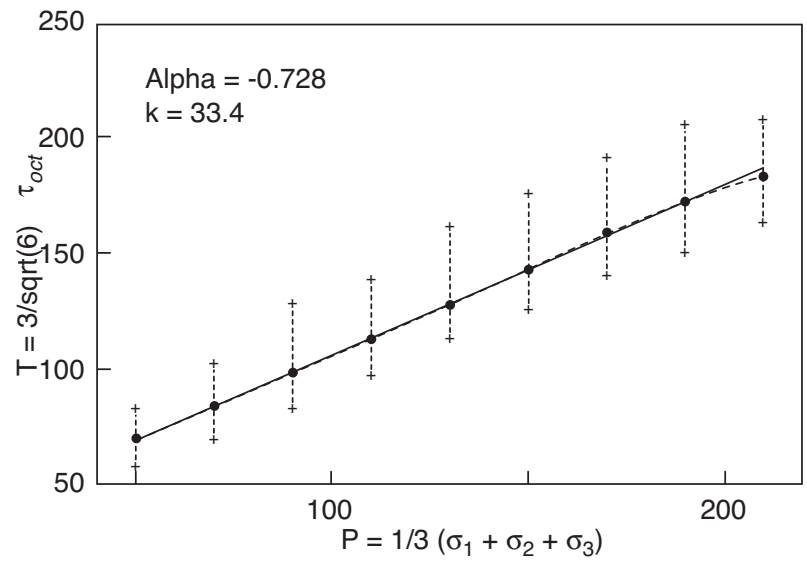

Figure 10

Fitting the parameters of the Drucker-Prager failure criterion for the Soignies limestone and for mean stresses ranging from 50 to $210 \mathrm{MPa}$. The plot also shows the min and max values of $T$ for each mean stress. whereas Figure 10 plots mean octahedral shear stresses. The minimum and maximum values of $\tau_{\text {oct }}$ for each octahedral plane are also plotted in Figure 10 to account for the scattering of the data.

\section{MODELLING THE GRIFFITH AND MURREL CRITERION}

\subsection{The Griffith and Murrel Criterion}

Within the framework of fracture mechanics, Griffith developed a two-dimensional criterion by considering the stress concentration at the tips of cracks and assuming that fracture is initiated when the maximum stress near the tip of the most favourably orientated crack reaches a characteristic value [16]. The Griffith's criterion is expressed as:

$$
\begin{gathered}
\left(\sigma_{1}-\sigma_{3}\right)^{2}=8 T_{0}\left(\sigma_{1}-\sigma_{3}\right) \text { if } \sigma_{1}+3 \sigma_{3}>0 \\
\sigma_{3}=-T_{0} \text { if } \sigma_{1}+3 \sigma_{3}<0
\end{gathered}
$$

where $T_{0}$ is the tensile strength of the material (Fig. 11). In the $\left(\sigma_{1}, \sigma_{3}\right)$ plane, the criterion is represented by a portion of straight line if $-T_{0}<\sigma_{1}<3 T_{0}$ and a portion of parabola if $\sigma_{1}>3 T_{0}$. With Equation 23, Griffith's theory assumes that the uniaxial compressive strength is given by $8 T_{0}$.

Murrel (1963, in [16]) extended the Griffith's criterion to three dimensions by simply generalizing its two geometrical properties. The parabolic part of the criterion becomes a portion of a revolution paraboloid inclined along the hydrostatic axis:

$\left(\sigma_{1}-\sigma_{2}\right)^{2}+\left(\sigma_{2}-\sigma_{3}\right)^{2}+\left(\sigma_{3}-\sigma_{1}\right)^{2}=24 T_{0}\left(\sigma_{1}+\sigma_{2}+\sigma_{2}\right)$

It is to notice that Equation 25 leads to a uniaxial compressive strength which equals twelve times the tensile strength

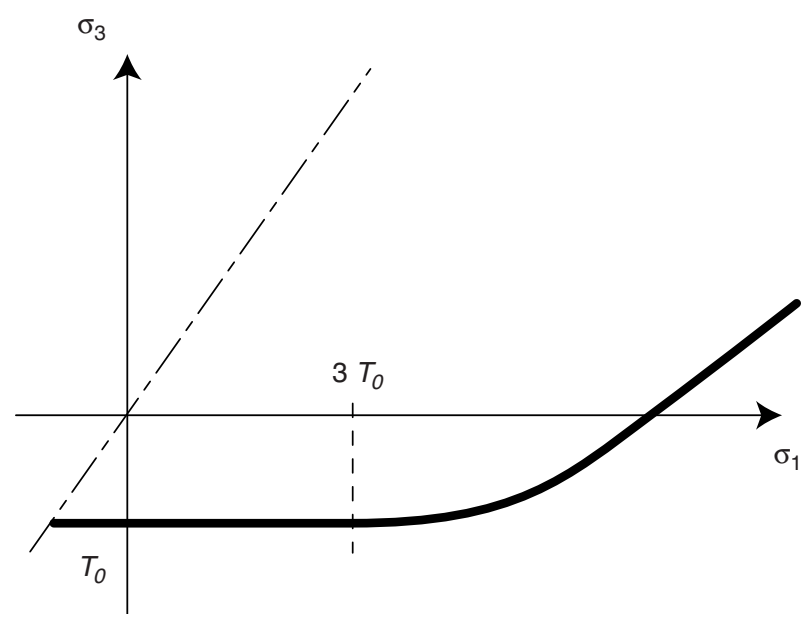

Figure 11

The two-dimensional Griffth criterion in the principal stress plane. $T_{0}$ is the tensile strength of the material. 


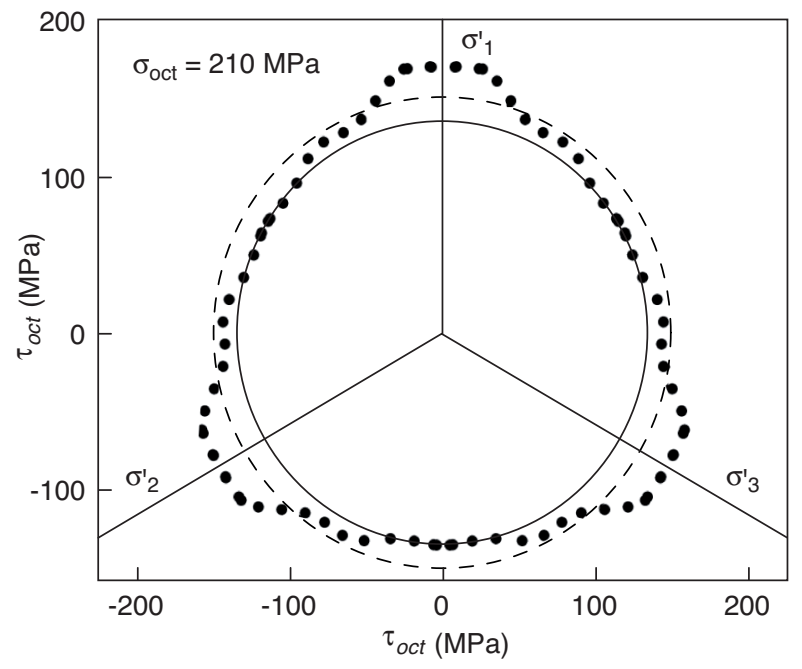

Figure 12

The Griffith and Murrel failure criterion in the $210 \mathrm{MPa}$ octahedral plane for the Soignies limestone. Modelling can be performed from data of a particular octahedral plane $\left(\sigma_{o c t}=\right.$ $210 \mathrm{MPa}$, dashed line) or of multiple octahedral planes $\left(50 \mathrm{MPa} \leq \sigma_{\text {oct }} \leq 210 \mathrm{MPa}\right.$, solid line).

in the case of Murrel's criterion. And the straight portion of the Griffith's criterion leads to a pyramid of mutually perpendicular planes:

$$
\sigma_{i}=-T_{0} \quad i=1,2,3
$$

The main advantage of Griffith and Murrel's theories is to provide a simple criterion to study the effects of polyaxial stresses. They indeed need only one parameter $\left(T_{0}\right)$ to build the failure surface.

\subsection{Modelling Method}

Introducing Equations 1 and 2 in Equation 25 gives:

$$
T_{0}=\frac{\tau_{o c t}^{2}}{8 \sigma_{o c t}}
$$

As for the Drucker-Prager criterion, the $T_{0}$ parameter can be considered for each octahedral plane or for a range of mean stresses, by averaging the values for multiple octahedral planes.

\subsection{Fitting the Criterion to the Soignies Limestone in the $210 \mathrm{MPa}$ Octahedral Plane}

In order to apply this criterion, the $T_{0}$ parameter is evaluated to 13.4 MPa using Equation 27, which is quite higher than the experimental value of the tensile strength for this material ( $8 \mathrm{MPa}$ ). This $T_{0}$ high value may be interpreted as a fictitious tensile strength, corresponding to a given range of confining stresses.

Modelling the Griffith-Murrel criterion by using Equation 27 implies the calculation of a value of the $T_{0}$ parameter for each octahedral plane. But it is also interesting to model the criterion with a single value of $T_{0}$ for a wider range of mean stresses. In the case of the Soignies limestone, we considered octahedral planes from 50 to $210 \mathrm{MPa}$ and we obtained a fictitious tensile strength of $10.7 \mathrm{MPa}$, which is closer to the experimental value.

Both results are plotted in Figure 12 where the dashed line corresponds to $T_{0}=13.4 \mathrm{MPa}$ and the solid line, to $T_{0}=10.7 \mathrm{MPa}$.

\section{MODELLING LADE-TYPE CRITERIA}

\subsection{The Lade Criterion and Associated Criteria}

The Lade criterion was first developed for cohesionless materials [20-22]. It is formulated in terms of the first $\left(I_{1}\right)$ and third $\left(I_{3}\right)$ invariants of the stress tensor:

$$
\left(\frac{I_{1}^{3}}{I_{3}}-27\right)\left(\frac{I_{1}}{P_{a}}\right)^{m}-\eta_{1}=0
$$

where $m$ and $\eta_{1}$ are material constants and $P_{a}$ is the atmospheric pressure. In the principal stress space, the failure surface is a pseudo-cone with the apex pointed at the origin (Fig. 13). In the octahedral plane, the criterion appears like a curvilinear triangle.

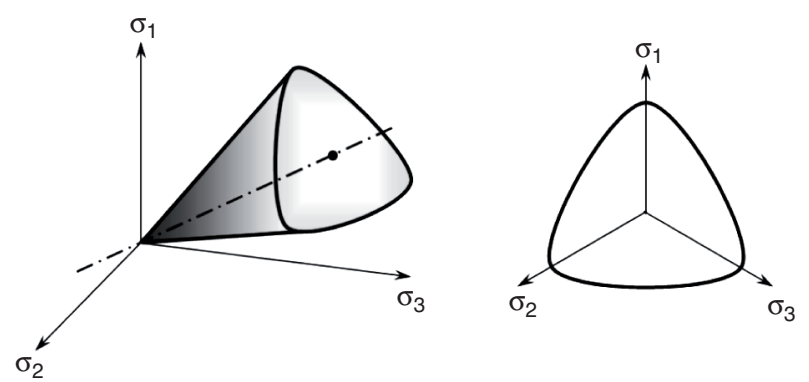

Figure 13

The Lade criterion in the three-dimensional principal stresses space (left) and in an octahedral view (right). 
In order to account for materials with cohesion and tensile strength, Kim and Lade translated the load surface along the hydrostatic axis [22] by adding a constant stress $a P_{a}$ to the normal stresses before substituting in Equation 28:

$$
\bar{\sigma}_{i j}=\sigma_{i j}+\delta_{i j} a P_{a}
$$

More recently, Ewy (1999 in [23]) proposed another variant of the criterion where the $m$ parameter is set to zero so that the shear strength increases linearly with $I_{1}$ [23]. He also took into account the cohesion of the material by adding the parameter $S$ to the normal stresses before substituting in Equation 28.

\subsection{Modelling Method}

Due to their mathematical expression, the Lade-type criteria are not so easy to fit and represent. In order to fit such criteria, the values of $m$ and $\eta_{1}$ are determined by plotting $\left(I_{1}^{3} / I_{3}-27\right)$ versus $\left(P_{a} / I_{1}\right)$ at failure in a log-log diagram and fitting the best straight line $[1,14]$. The intercept of this line with $\left(P_{a} / I_{1}\right)=1$ gives the value of $\eta_{1}$ whereas $m$ represents its slope. In the case of modified Lade criteria, the data should first be translated along the hydrostatic axis by taking into account the tensile strength of the material (parameters $a$ or $S$ ).

For representing the results in the octahedral plane, we propose the following method. When considering a particular deviatoric plane, the value of $I_{1}$ is known:

$$
I_{1}=\sigma_{1}+\sigma_{2}+\sigma_{3}=3 \sigma_{o c t}
$$

Therefore, $I_{3}$ is also determined by Equation 28:

$$
I_{3}=\sigma_{1} \sigma_{2} \sigma_{3}=\frac{I_{1}^{3}}{\eta_{1}\left(\frac{P_{a}}{I_{1}}\right)^{m}+27}
$$

The octahedral modelling of the criterion results in solving a system of two Equations 30 and 31 with three unknowns $\left(\sigma_{1}, \sigma_{2}, \sigma_{3}\right)$.

From Equation 30, we have:

$$
\sigma_{2}=I_{1}-\sigma_{1}-\sigma_{3}
$$

This relation is introduced in Equation 31 and gives:

$$
I_{1} \sigma_{1} \sigma_{3}-\sigma_{1}^{2} \sigma_{3}-\sigma_{1} \sigma_{3}^{2}-I_{3}=0
$$

For a given value of $\sigma_{1}$, Equation 33 becomes a second degree polynomial of $\sigma_{3}$, the roots of which give the values of $\sigma_{2}$ and $\sigma_{3}$.

The range of $\sigma_{1}$ values is determined by solving the system of Equations 30 and 31 for two particular cases: the triaxial $\left(\sigma_{2}=\sigma_{3}\right)$ and biaxial $\left(\sigma_{2}=\sigma_{1}\right)$ stress states. For the triaxial stress states, we have:

$$
2 \sigma_{3}^{3}-I_{1} \sigma_{3}^{2}+I_{3}=0
$$

Among the three roots of this polynomial, solutions such that $\sigma_{3}<0$ or $\sigma_{1}<\sigma_{3}$ are not valid and the third root gives the value of $\sigma_{1}$. In the case of biaxial stress states, we have:

$$
2 \sigma_{1}^{3}-I_{1} \sigma_{1}^{2}+I_{3}=0
$$

Once again, three roots will be found but the condition $0<\sigma_{1}<\sigma_{3}$ eliminates two of them.

\subsection{Fitting the Criteria to the Soignies Limestone in the $90 \mathrm{MPa}$ Octahedral Plane}

Figure 14 shows the results of the modelling of the failure envelope in the $90 \mathrm{MPa}$ octahedral plane by Lade-type criteria.

Firstly, we modelled the envelope according to the KimLade criterion, taking into account the tensile strength of the rock $(8 \mathrm{MPa})$. For determining the parameters of the criterion, we plotted $\left(I_{1}^{3} / I_{3}-27\right)$ versus $\left(P_{a} / I_{1}\right)$ in a log-log diagram for the triaxial states at failure (Fig. 15). The intercept of the best fitting straight line gives the value of $\eta_{1}=2.40 \times$ $10^{23}$. But the $m$ parameter has to be fitted for each octahedral plane to give satisfactory results. For a mean stress of $90 \mathrm{MPa}$, we found $m=6.41$.

Secondly, we modelled the failure envelope with the Ewy's criterion in which the tensile strength is accounted for by means of the $S$ parameter. In this case, $m$ is set equal to 0 so that computing $I_{1}^{3} / I_{3}-27$ for the triaxial stress states

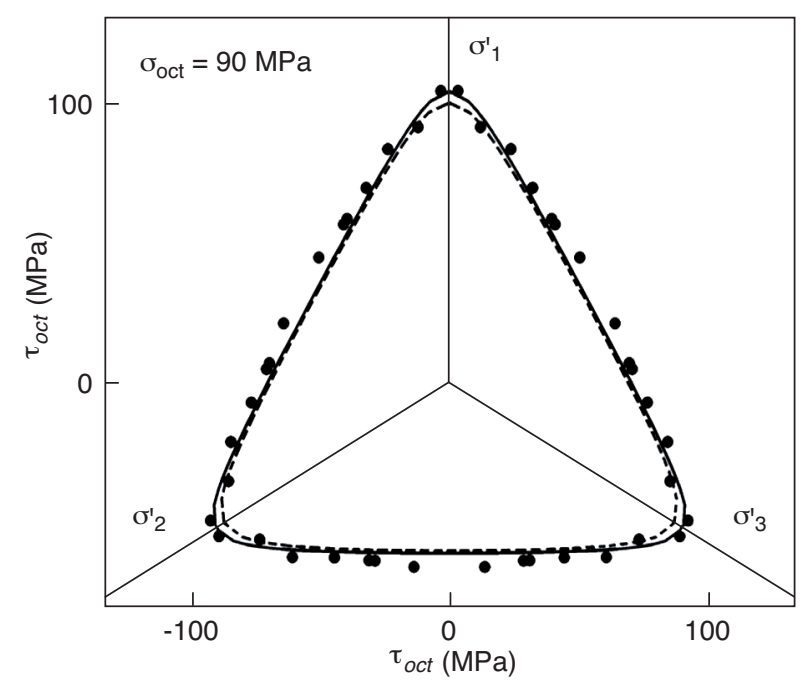

Figure 14

The Kim-Lade (solid line) and Ewy (dashed line) failure criteria in the $90 \mathrm{MPa}$ octahedral plane for the Soignies limestone. 


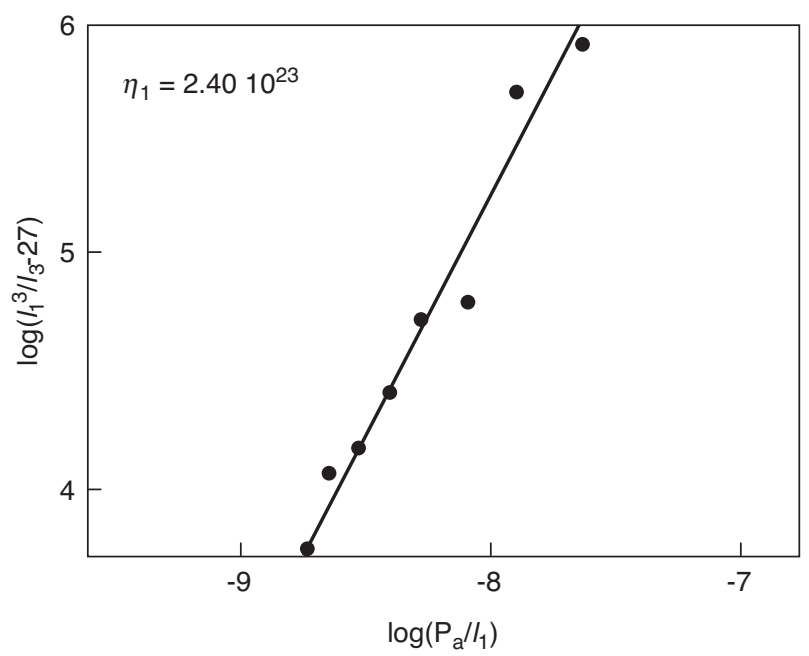

Figure 15

Fitting the parameters of the Kim-Lade criterion for the Soignies limestone.

directly leads to a value of $\eta_{1}$ for each octahedral plane. The values of $\eta_{1}$ are found to be strongly dependent on the mean stress. For a mean stress of $90 \mathrm{MPa}$, we have $\eta_{1}=209$.

The Kim-Lade and Ewy criteria are both illustrated in Figure 14 and are in good agreement with the interpolated data. Although the Kim-Lade criterion seems to give better results near the triaxial states, it is of interest to point out that the Ewy's criterion only needs two parameters (instead of three for the Kim-Lade one) and also leads to very good results in this particular case.

\section{CONCLUSION}

The octahedral representation is particularly convenient to take the influence of the three principal stresses into account in the building and modelling of limiting envelopes.

In this paper, we first remind the method we developed to build limiting envelopes of rocks. In the case of the Soignies limestone, the shape of the octahedral failure envelopes evolves with the mean stress: from an almost triangular envelope at the lower mean stresses (90 MPa), the failure surface becomes hexagonal (130 MPa) and then more rounded (210 MPa).

Following this observation, we focused on some classical failure criteria to model the limiting envelopes: MohrCoulomb, Drucker-Prager, Griffith-Murrel and Lade criteria. The theoretical background of each criterion is reminded and the modelling methods are detailed. Each criterion is then applied to a particular octahedral failure envelope of the
Soignies limestone: the Mohr-Coulomb criterion is applied for hexagonal envelopes, the Drucker-Prager and GriffithMurrel criteria are used for rounded envelopes and the Ladetype criteria are applied to triangular envelopes. In each case, the parameters of the criterion are computed.

In this paper, we modelled octahedral envelopes by choosing some classical criteria based on the shape exhibited by experimental data; this is quite subjective. In the future, we are going to fit other criteria such as Hoek-Brown, Matsuoka-Nakai, ... or generalised load functions like those proposed by Bigoni and Piccolroaz [10] or Yu et al. [9]. Furthermore we will try to estimate the quality of the fitting by means of a quantitative parameter; and hence, be able to determine which criterion is the most appropriate for modelling a set of experimental data.

As far as we used the classical criteria, we observed that one single model is not enough to fit the variety of octahedral shapes observed for a given material. An attempt can be made to develop a specific criterion that could fit a wide range of experimental data in terms of mean stresses.

\section{ACKNOWLEDGEMENTS}

FD thanks the Belgian National Fund for Scientific Research (F.N.R.S.) for her Research Fellow position.

\section{REFERENCES}

1 Tshibangu J.P. (1993) Étude des effets du confinement sur le comportement mécanique des roches pour application au calcul des ouvrages souterrains, Thèse, Faculté Polytechnique de Mons.

2 Tshibangu J.P. (1997) The effect of a polyaxial confining state on the behaviour of two limestones, Environmental and Safety Concerns in Underground Construction, New-York, 06/1997.

3 Mogi K. (1967) Effect of the intermediate principal stress on rock failure, J. Geophys. Res. 72, 5117-5131.

4 Takahashi M., Koide H. (1989) Effect of the intermediate principal stress on strength and deformation behaviour of sedimentary rocks at the depth shallower than 2000 m, Rock at Great Depth, Maury \& Fourmaintreaux (eds.), Pau, 08/1989.

5 Haimson B., Chang C. (2000) A new true triaxial cell for testing mechanical properties of rock and its use to determine rock strength and deformability of Westerly granite, Int. J. Rock. Mech. Min.37, 285-296.

6 Colmenares L.B., Zoback M.D. (2002) A statistical evaluation of intact rock failure criteria constrained by polyaxial test data for five different rocks, Int. J. Rock Mech. Min. 39, 695-729.

7 Colmenares L.B. (2004) Rock strength under true triaxial loading, seismotectonics of Northern South America and geomechanics and coal bed methane production in the Powder River Basin, PhD Thesis, Stanford University.

8 Michelis P. (1985) Polyaxial yielding of granular rock, J. Eng. Mech. 111, 8, 1049-1066.

9 Yu M.H., Zan Y.W., Zhao J., Yoshimine M. (2002) A Unified Strength criterion for rock material, Int. J. Rock Mech. Min. 39, 975-989. 
10 Bigoni D., Piccolroaz A. (2004) Yield criteria for quasibrittle and frictional materials, Int. J. Solids Struct. 41, 2855-2878.

11 Comité Français de Mécanique des Roches (2000) Manuel de Mécanique des Roches, Tome 1, Presses de l'École des Mines de Paris, Paris.

12 Charlez P.A. (1991) Rock Mechanics - Theoretical Fundamentals, Technip, Paris.

13 Descamps F., Tshibangu J.P. (2006) An automated procedure to build failure envelopes and model the Mohr-Coulomb criterion in the three-dimensional principal stresses space from polyaxial test data, Eurock 2006, Liège, 05/2006.

14 Flatebǿ R.E., Risnes R. (2001) Application of three dimensional failure criteria on high-porosity chalk, 6th Nordic Symposium on Petrophysics, Trondheim, Norway, 05/2001.

15 Vutukuri V.S., Lama R.D., Saluja S.S. (1974) Handbook on mechanical properties of rocks, Vol. 1, Trans. Tech. Publications.

16 Jaeger J.C., Cook N.G.W. (1979) Fundamentals of Rock Mechanics, Chapman and Hall, London.
17 Drucker D., Prager W. (1952) Soil mechanics and plastic analysis of limit design, Q. Appl. Math. 10, 157-165.

18 Desrues J. (2002) Limitations du choix de l'angle de frottement pour le critère de plasticité de Drucker-Prager, R.F.G.C. 6, $853-862$.

19 Coussy O. (1991) Mécanique des Milieux Poreux, Technip, Paris.

20 Lade P.V. (1977) Elasto-plastic stress-strain theory for cohesionless soil with curved yield surfaces, Int. J. Solids Struct. 13, 1019-1035.

21 Kim M.K., Lade P.V. (1984) Modelling rock strength in three dimensions, Int. J. Rock Mech. Min. \& Geomech. Abstr. 21, 21-33.

22 Lade P.V., Kim M.K. (1995) Single hardening constitutive model for soil, rock and concrete, Int. J. Solids Struct. 32, 1963-1978.

23 Ewy R. (1999) Wellbore-stability predictions by use of a modified Lade criterion, SPE Drill Completion 14, 2, 85-91.

Final manuscript received in June 2007 or distributed for profit or commercial advantage and that copies bear this notice and the full citation on the first page. Copyrights for components of this work owned by others than IFP must be honored. Abstracting with credit is permitted. To copy otherwise, to republish, to post on servers, or to redistribute to lists, requires prior specific permission and/or a fee: Request permission from Documentation, Institut français du pétrole, fax. +33147527078 , or revueogst@ifp.fr. 